\title{
S
}

В.Л. Жданов

\section{КОСМИЧЕСКАЯ ПОЛИТИКА КАК СФЕРА МЕЖДИСЦИПЛИНАРНЫХ ИССЛЕДОВАНИЙ И КАК ОБЪЕКТ ПОЛИТОЛОГИЧЕСКОГО АНАЛИЗА}

\begin{abstract}
Аннотация: В статье рассматривается необходимость применения в изучении космической политики междисциплинарного подхода, так как область исследований в этой сфере требует «соучастия» множества наук, связанных с космосом и космонавтикой, но и через классическое понимания концепта «политика» во всем его многообразии. Анализируются труды деятелей науки в области космоса и космической политики не только отечественных, таких как В.И. Вернадский, В.Н. Гущин и Б.С. Соколов, но зарубежных - Д. Пайсона. Выделяются определенные подходы к изучению космической политики, в частности такая методология как функичональная, сравнительная, социологический, политико-культурный. Отмечается, что наиболее перспективными для изучения космической политики, являются междисииплинарный подход и политологический анализ.
\end{abstract}

Ключевые слова: Политология, космическая политика, междисциплинарный подход, политологический подход, методологический подход, политологическая парадигма, межгосударственные отношения, международные отношения, геополитические школы, космическая деятельность

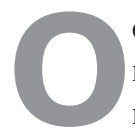
сознание принципиального единства, целостности мира на всех его уровнях - от микро и макро до мегамасштабов Вселенной и Космоса, от преджизненных феноменов до сложных социальных формирований и коммуникаций - диктует насущную необходимость создания такой универсальной науки, которая по-возможности адекватно отражала бы это сущностное внутреннее единство реального мира. Безусловно, на сегодняшний день это скорее идеал, некий парадигматический эталон, на который ориентируется мировое научное сообщество, - однако стоит отметить характерный факт: все более широкомасштабная универсализация знания, размывание его конкретнонаучных границ происходит словно бы вне зависимости от желания либо нежелания носителей научного знания (ученых, исследователей, специалистов или их ассоциаций - научных коллективов, школ и течений), и уж тем более не по какой-то указке «сверху», из управляющих структур. Синтез, сочетание, постоянное углубление взаимодействия и взаимовлияния демонстрируют себя как проявления сложной исторической закономерности, может быть, еще не вполне осознанной нами - зато в достаточной мере прочувствованной.

«В наше время рамки отдельной науки, на которые распадается научное знание, не могут точно определять область научной мысли... Мы специализируемся не по наукам, а по проблемам... Иногда, довольно часто, бывает возможно выразить в названии новой дисциплины сложный характер ее содержания, принадлежность как научных фактов новой дисциплины, так и ее методик, ее эмпирических обобщений, ее ведущих основных идей, научных гипотез и теорий к разным старым научным областям...»[1, стр. 94].

Специализация, как сформулировал этот процесс В.И. Вернадский, «не по наукам, а по проблемам», функционирование различных областей человеческого познания «на стыке», «на грани», в некоем пограничном пространстве, давно миновав стадию экзотической новинки, превратились в почти обыденный факт академической реальности. Область политических исследований и их методологических основ - одна из тех сфер, где процессы подобной интеграции заявляют о себе особенно активно и наглядно; ее десятилетиями подпитывают методы, разработанные не только в смежных, так называемых общественных, науках, таких как социология, социальная психология, демография или социальная антропология, но и во все более отдаленных по предмету и объекту изысканий. Что касается собственно космической политики, и без специального семантического анализа этого термина легко увидеть, что он изначально предполагает интенсивное применение междисциплинарного подхода. Ибо представляется совершенно ясным, что область исследований в этой сфере определяется не только на основе космологических категорий, что само по себе требует «соучастия» множества наук, связанных с космосом и космонавтикой, 


\section{Право и политика $3(159) \cdot 2013$}

но и через классическое понимания концепта «политика» во всем его многообразии.

Можно выделить следующие подходы к изучению космической политики:

- $\quad$ функциональная методология, позволяющая оценить корреляцию между явным проявлением реальных политических процессов и космической политикой (Версальский мирный договор спровоцировал развитие ракетостроения в Германии, биполярность мира нашла свое отражение в ускоренном освоении космоса СССР и США), выявить закономерности, характеризующие зависимость «космической активности» общества от уровня его экономического развития и тому подобное;

- $\quad$ сравнительная методология также является незаменимым инструментом, ибо позволяет на основе сравнительного анализа космических программ различных государств раскрыть основные тренды и определить наиболее критичные проблемы космической политики в целом, как самостоятельного проявления общественно-политической деятельности всего человечества;

- социологический подход позволяет исследовать космическую политику сквозь призму общественных отношений, в том числе в контексте развития производительных сил того или иного космического актора, будь то государство, наднациональное образование (Европейский Союз) или некая транснациональная корпорация, оперирующая в космическом пространстве, - то есть осуществляющая собственную, отличную от государства регистрации, космическую политику;

- $\quad$ с двумя последними пересекается подход политикокультурный, изучающий как институциональную организацию общества, так и специфику общественного восприятия институтов социума в каждой конкретной культуре.

Специфика политологического подхода при анализе космической политики требует осмысливать явления, соотнесенные с освоением космоса, как феномены именно социально-политической активности. Ибо и инициатором, и проводником космической политики, и конечным потребителем ее плодов и результатов - от военного, правового, экономического ракурса до таких пока экзотических направлений, как «туристическое», - являются государственные и общественные институты, общество в целом. Политологическая парадигма, другими словами, позволяет анализировать космическую политику как целостное общественно-политическое явление, в то время как интерпретация ее в других измерениях дает более узкий обзор. Собственно, это, по мнению автора, как раз и предопределяет преимущества политологического подхода к оценке и анализу космической политики как знакового социального явления, заведомо включающего в свои рамки проблематику экономики и экологии, научно-технического прогресса и культуры, морали и этики.

Если рассматривать космическую политику как один из элементов некой государственной доктрины, то она представляется в виде программных документов, таких как US Space Policy или China Space Activities, которые не только регламентируют взаимодействие государственных институтов, но и в декларативной форме расставляют свои приоритеты: безопасность, наука, коммерция и т.д.; анализируя выстраивающуюся в результате иерархию поставленных целей, возможно составить некую целостную картину.

Кроме того, тема космической политики - предмет особого внимания для исследователей межгосударственных и международных отношений, а также для представителей геополитических школ всех направлений, особенно в контексте «космического потенциала» или «Space facilities» - как некого аналога «до-космических» категорий типа «Der Lebensraum» и «The Sea Power».

Юрист, исследуя соотношение космической политики и права, сделает акцент на объективности и профессиональном уровне правовой оценки изучаемых им аспектов регулирования космической деятельности. Ее юридическое «сопровождение»- одна из актуальнейших на сегодня граней космической политики в свете явно недостаточной разработанности нормативной документации в этой сфере.

Экономисты также не могут оставаться в стороне, оценивая космическую политику через собственно-экономический понятийный аппарат. Анализ экономической эффективности мощных капиталовложений в космические объекты невозможен на основе одного лишь знания экономической теории; такой анализ требует глубокого понимания специфики данной сферы. Для экономиста космическая политика есть совокупность макроэкономики (годовой оборот около 17 млрд. \$) и котировок на Франкфуртской фондовой бирже акций компаний SES из Великого Княжества Люксембург - обладателя крупнейшего в мире орбитального флота. Общее впечатление от космической политики у некоторых экономистов не самое радужное - они видят в ней безответственную трату бюджетных средств: в 2008 г. в мировом масштабе было потрачено более 35 млрд. \$ [2, стр. 52], а выручка космических операторов в том же году была в два раза меньше. Другими словами, в экономическом измерении космическая политика пока воспринимается как некое «рискованное предприятие», во всяком случае, если оценивать деятельность государственных институтов по освоению космоса. Достаточно эмоционально выразил эту популярную позицию В.Н. Гущин в докладе «Грамотная космическая политика - основа могущества страны»: «Надо ли сегодня так уж рваться в Космос, как это было на заре космической эры? В период романтизма и сопер- 
ничества? Или следует остановиться и подумать, а туда ли мы движемся... Мы уже неоднократно делали гигантские рывки в Космос, удивляя все человечество, но не тем, чем мы думали его удивить. Разумный баланс в распределении инвестиций по важнейшим отраслям народного хозяйства и есть основа могущества...» [3].

С естественнонаучной точки зрения космическая политика есть уникальный шанс «осознания» окружающего нас мира и «осмысления» законов, его определяющих. Для физика, химика или биолога - космическая политика суть уникальный инструмент изучения, позволяющий перейти от «мнения» об объекте изучения непосредственно к его изучению. Именно космической политике, как регулятору (посредством государственных и общественных институтов), в том числе и научной составляющей космической деятельности, мы обязаны рождением и множества междисциплинарных наук - астрофизика, космическая биология и др., - а так же целого спектра научных открытий, которые были бы попросту невозможны вне космоса и практик, с ним связанных. Тесно связан с естественнонаучным и технико-технологический аспект.

Соотношение космической политики и экологии могло бы стать темой отдельной диссертации, так как целый «букет» экологических угроз напрямую связан с темой освоения космоса. Угроза ядерной войны, которая, как предполагается, должна вестись баллистическими арсеналами через космос, - это раз. Тысячи квадратных километров вокруг космодромов, находящихся в зоне перманентного экологического бедствия, виной чему падающие ступени разгонных блоков с остатками крайне опасного в экологическом отношении ракетного топлива, - два. Проблема космического мусора, постепенно «закупоривающего» нас в месте привычного обитания (Земля + 110 км вверх) - три; к сожалению, список экологических угроз на этом далеко не заканчивается. Космическая политика, в зависимости от тех или иных тенденций ее развития, может способствовать либо дальнейшему расширению этого печального списка, либо - при достаточно компетентном, взвешенном и ответственном принятии решений в ее рамках - хотя бы относительному смягчению экологической напряженности.

Космическая политика - своего рода индикатор развития общества, анализируя который, как некую производную от функциональных показателей всего общественного развития - политического, экономического, научного и т.п., можно дать более-менее целостную «картину» всего общества.

Существует еще один нюанс, тесно связанный с обсуждаемой проблемой и затронутый в статье к.т.н. Д. Пайсона [4, стр. 41]: «На протяжении прошедшего десятилетия в российской КД (космической деятельности - В.Ж.) появилась реальная субъектность. Разнящиеся в условиях нецентрализованной экономики интересы участников КД... привели к тому, что недостаточно стало лишь указывать на более или менее оптимальный вариант того или иного программного или технического решения. Требуется уточнение: с чьей точки зрения «оптимальный». Естественно, интересы промышленности и заказчиков расходились и в плановой экономике, но в ней существуют прямые административные инструменты согласования в рамках сквозного государственного планирования... В условиях, когда нет государственного планирования деятельности промышленности, ...необходима иная система, направленная на формирование компромиссов между несколькими взаимодействующими интересами» [4, стр. 41].

В своей работе мы пришли к выводу, что вопрос о критериях истинности исследования стоит особо остро в связи с идеологизированно-административным наследием, доставшимся нам от советского прошлого; теперь обнаруживаем, что особую остроту ему придает как раз отказ от этого наследства. Разрешение подобных противоречий возможно, опять же, лишь при принятии факта условности и относительности научной истины...

Мы не претендуем на - опять цитируя Соколова - «изощренность аргументации и непререкаемость доводов», однако представляется также, что и российское обществоведение достаточно созрело для того, чтобы принять энергичное участие в обсуждении эпистемологических проблем научного исследования, оказавшихся в центре внимания наших западных коллег. Но если даже ученым придется смириться с тем, что добытая их «кровью и потом» научная истина всегда останется относительной и зависимой от конкретных условий, - тем большую значимость обретает исследование и анализ этих самых «конкретных условий» (в контексте космической политики - прежде всего условий социально-политических). Следовательно, и вопрос о применяемых в исследовании методологических подходах остается одним из важнейших в повестке дня.

Подводя итог всему выше сказанному, необходимо отметить, что изучение космической политики предполагает интенсивное применение междисциплинарного подхода. Однако когда объектом изучения самых разных дисциплин оказывается космическая политика, ее собственные особенности как объекта определяют и специфику исследовательского подхода. Проблема, актуальная для любого научного исследования, а для исследования космической политики в частности, это вопрос о критерии истинности и границах применимости научного знания.

\section{Библиография:}

1. Вернадский В.И. Научная мысль как планетное явление. - М.: Наука, 1991. 271 с. 


\section{Право и политика 3 (159) • 2013}

2. Жданов В.Л. Экономические перспективы космической политики России на современном этапе. - М.; Екатеринбург, 2009. 121 с.

3. Космонавтика и устойчивое развитие общества. URL: http://www.ihst.ru/ akm/c9.htm (дата обращения 15.09.2009).

4. Пайсон Д.Б. Перспективы российского космоса. Основные особенности парадигмы институционального проектирования в области космической деятельности // Двигатель. 2009. № 4 (64).

\section{References (transliteration):}

1. Vernadskiy V.I. Nauchnaya mysl' kak planetnoe yavlenie. - M.: Nauka, 1991. $271 \mathrm{~s}$.

2. Zhdanov V.L. Ekonomicheskie perspektivy kosmicheskoy politiki Rossii na sovremennom etape. - M.; Ekaterinburg, 2009. $121 \mathrm{~s}$.

3. Payson D.B. Perspektivy rossiyskogo kosmosa. Osnovnye osobennosti paradigmy institutsional'nogo proektirovaniya $\mathrm{v}$ oblasti kosmicheskoy deyatel'nosti // Dvigatel'. 2009. №4 (64). 